\title{
Sustainable Development as a Meta-Context for Engineering Education
}

\author{
Karel Mulder $^{* 1}$, Cheryl Desha ${ }^{2}$, Karlson Charlie Hargroves ${ }^{3,4}$ \\ ${ }^{1}$ Delft University of Technology \\ e-mail: k.f.mulder@tudelft.nl \\ ${ }^{2}$ Queensland University of Technology, Brisbane, Australia \\ The Natural Edge Project \\ ${ }^{3}$ University of Adelaide, Adelaide, Australia \\ ${ }^{4}$ Curtin University, Perth, Australia \\ The Natural Edge Project
}

Cite as: Mulder, K., Desha, C., Hargroves, K.C., Sustainable Development as a Meta-Context for Engineering

Education, J. sustain. dev. energy water environ. syst., 1(4), pp 304-310, 2013, DOI:

http://dx.doi.org/10.13044/j.sdewes.2013.01.0023

\begin{abstract}
At the end of the first decade of the twenty-first century, there is unprecedented awareness of the need for a transformation in development, to meet the needs of the present while also preserving the ability of future generations to meet their own needs. However, within engineering, educators still tend to regard such development as an 'aspect' of engineering rather than an overarching meta-context, with ad hoc and highly variable references to topics. Furthermore, within a milieu of interpretations there can appear to be conflicting needs for achieving sustainable development, which can be confusing for students and educators alike. Different articulations of sustainable development can create dilemmas around conflicting needs for designers and researchers, at the level of specific designs and (sub-) disciplinary analysis. Hence sustainability issues need to be addressed at a meta-level using a whole of system approach, so that decisions regarding these dilemmas can be made. With this appreciation, and in light of curriculum renewal challenges that also exist in engineering education, this paper considers how educators might take the next step to move from sustainable development being an interesting 'aspect' of the curriculum, to sustainable development as a meta-context for curriculum renewal. It is concluded that capacity building for such strategic considerations is critical in engineering education.
\end{abstract}

\section{KEYWORDS}

Sustainable development, Meta-context, Engineering education, Whole of system approach, Dynamic and deliberative curriculum renewal.

\section{INTRODUCTION}

\section{Engineering Education \& Sustainable Development}

At the aggregate level of the whole planet Earth and global society, sustainable development is clearly defined, with many textbooks on the topic and the role of education [1-3]. Indeed, in commenting that 'Engineers play a key role in sustainable development', one can achieve a pleasant start of any discussion on the topic in the engineering community. Such a discussion soon highlights how sustainable development is not about blaming technology and industry for the polluting and wasteful society that we live in but rather that engineering is a key part of the solution in successive waves of innovation [4, 5]. As shown

* Corresponding author 
in Figure 1, the fifth wave of innovation, which occurred towards the end of last century, provided a new technological platform and numerous tools for development. However, alongside these achievements, society now faces a host of emerging challenges and opportunities under the sustainable development umbrella. These may include reducing greenhouse gas emissions, addressing climate change adaptation needs, diminishing the equity gap, dealing with resource scarcity and creating solutions that decouple economic growth from negative environmental pressure [6].

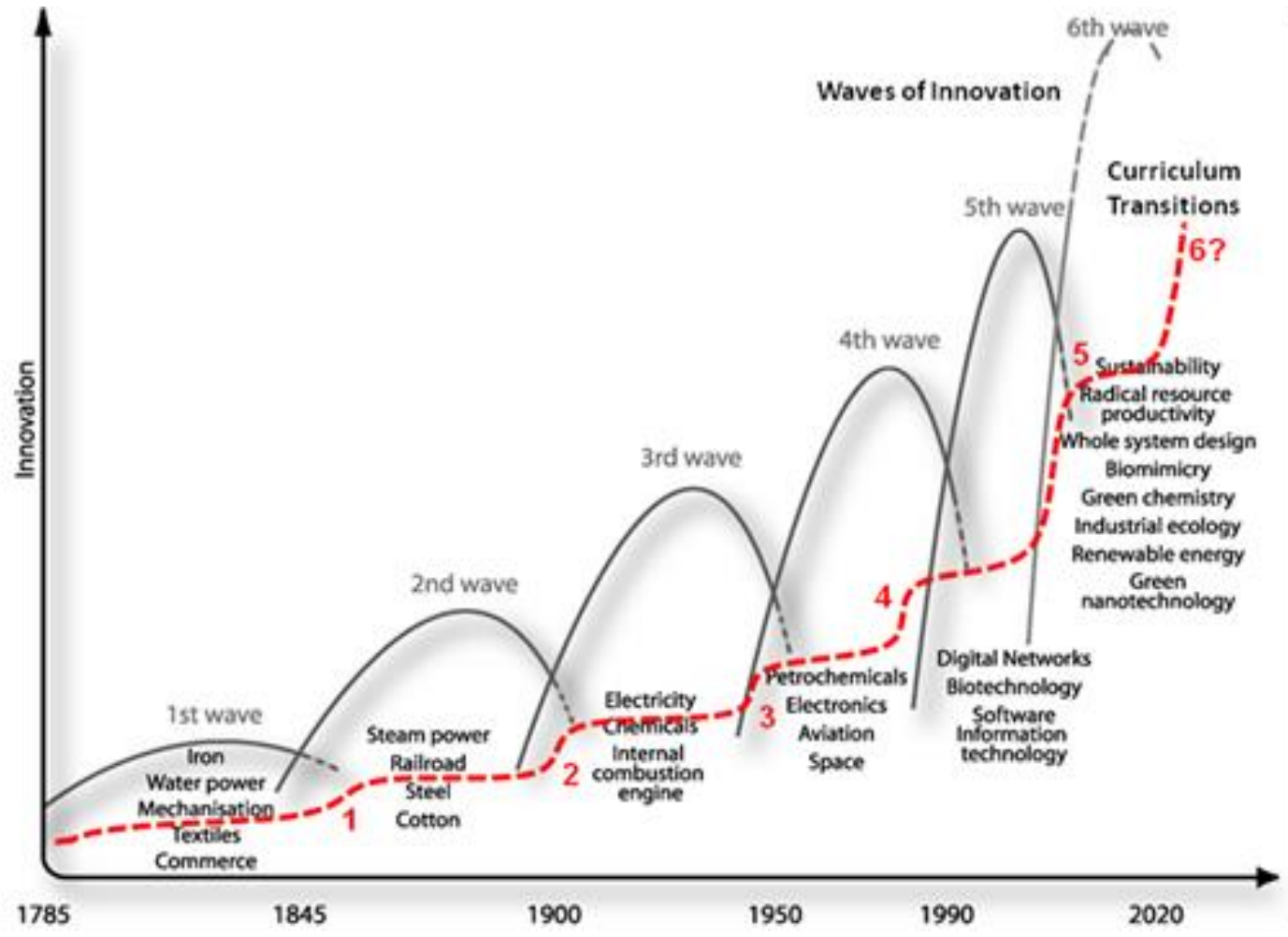

Figure 1. A schematic of curriculum renewal transitions, following significant waves of innovation [6]

In the sixth wave, the engineering profession plays a key role in responding to these emerging challenges, drawing upon knowledge and skill sets across all disciplines in new areas such as resource productivity, energy efficiency, whole system design, and bio mimicry (i.e. design inspired by nature). Within this context, if engineers have such a crucial role they should know where they are heading, and their curriculum should enable them to pursue that pathway. Unfortunately, more than two decades after seminal publications such as 'Our Common Future' [7], and with cautionary reminders such as the 'Stern Review' [8], 'Plan B' [9] and emerging engineering related sustainability text books such as 'Factor 5' [4] and 'Cents and Sustainability' [5], around the world sustainable development still appears as add-on modules in the curriculum, with limited knowledge and skill development or embedding through content and assessment [10].

Globally there are few engineering programs that may claim to have embedded sustainability within the curriculum [11-14]. Instead, most engineering programs still define themselves as a discipline which means that there is a core set of knowledge. Then, sustainable development is one 'aspect' or consideration to be covered as far as it touches their particular discipline, for example in civil, electronic, environmental, and mechanical engineering and so on. Furthermore, the traditional amount of time needed/ required to undertake a full-scale curriculum transition (in the order of two decades) is exceeding the 
available window for equipping professionals with critical new graduate attributes. This is a significant time lag dilemma facing educators, and is highlighted by the dotted line in Figure 1 [10]. There are few examples of systemic curriculum renewal that meet the recommended timeframe of one decade, or discussion of how curriculum renewal could be undertaken over such contracted timeframes.

A significant challenge within this state of affairs is that by sustainable development being merely an additional aspect of each discipline's considerations, it does not provide the central (or underpinning) context for the curriculum. Furthermore, an aspect may be dropped or replaced due to any number of bureaucratic pressures without much ado. In summary, being an aspect lends the topic area to vulnerability, where critical knowledge and skill areas may be deleted or replaced without systemic consideration of learning consequences.

With this in mind, the question we consider herein is how might engineering educators take the next step: moving from sustainable development as an interesting aspect for the engineer, to sustainable development as a meta-context for curriculum renewal? Furthermore, in a profession with many sub-disciplines and various phases of design, how do we develop a curriculum that avoids creating dilemmas around conflicting needs for designers and researchers?

\section{Engineering Education \& Curriculum Renewal}

Intertwined with the challenge of embedding a substantial new knowledge and skill area within the engineering curriculum, Desha and Hargroves highlight the challenge of undertaking the process of engineering curriculum renewal itself [6]. The last century's engineering education literature clearly highlights a shortfall in the ability of the curriculum to respond to changes in graduate demands. In particular, enquiry by these authors into a number of earlier models by leaders in the field over the last half century, including Tyler, Taba, Wheeler, Kerr, Walker, Stenhouse and Egan, uncovers a lack of a whole of system approach to curriculum renewal in the higher education sector that has two significant implications:

- The ad hoc process inevitably leads to delays and inefficiencies in curriculum renewal processes; and

- There is no systematic way to build central themes and meta-context into the curriculum.

It is no wonder then, that there have been so many difficulties in embedding sustainability into the curriculum to date. In responding to this challenge, Desha and Hargroves have developed a model that can provide a strategic framework for renewal, wherein any new knowledge and skill set could be systemically embedded into the curriculum.

Beginning with the curriculum renewal strategy (centre of diagram), this model highlights the importance of having a central point of reference when undertaking systematic curriculum renewal, particularly when multiple educators are involved (in this case the context of 'education for sustainable development'). The arrows immediately around this text remind us that the strategy needs to inform each and every stage of curriculum renewal. In the five larger circles around the central strategy, the five key steps in curriculum renewal link in an iterative process that reminds us of the need for substantial planning and investigation before individual units are revised. The arrows interacting with the outer circle remind us that this stepped process also requires continual monitoring and evaluation, internal and external collaboration, and awareness raising and capacity building among staff. Furthermore, the steps are informed by, and also inform, the three activities in the outer circle. 


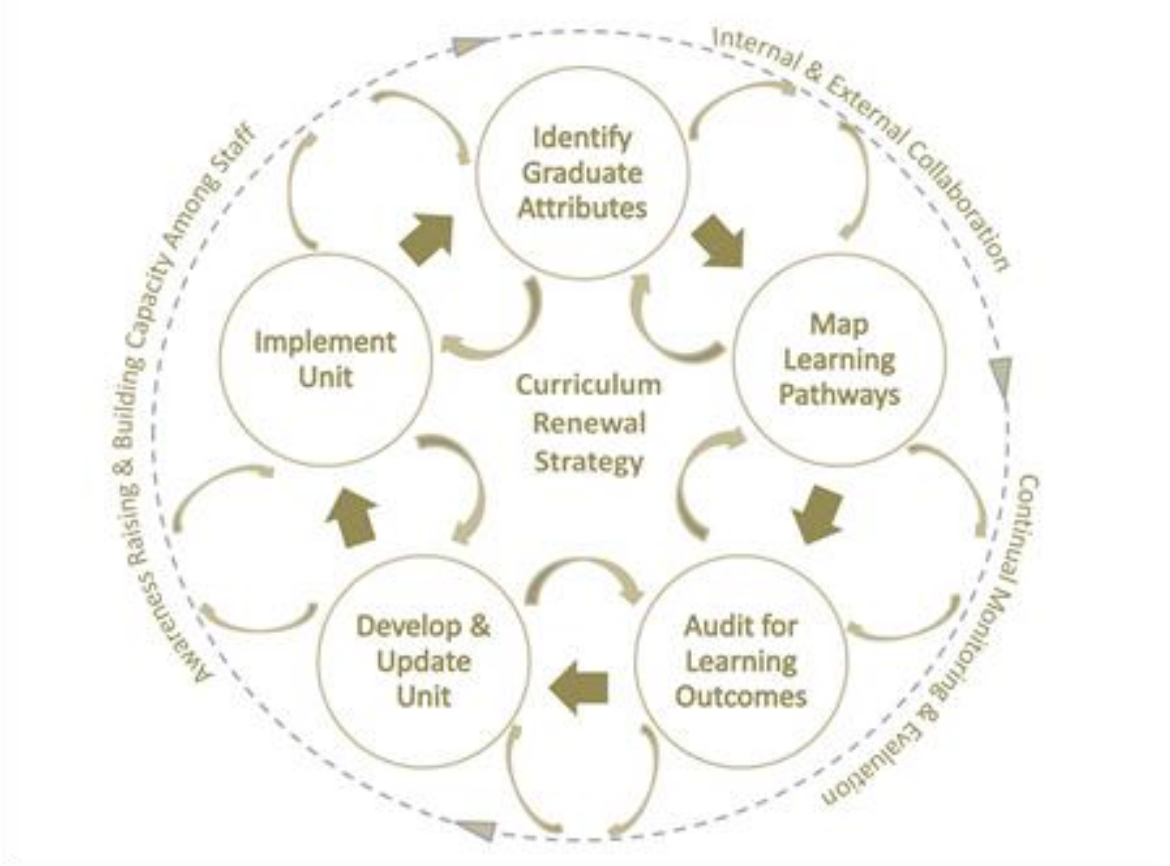

Figure 2. The Desha-Hargroves Deliberative and Dynamic Model for Curriculum Renewal [6]

In summary, by using such a model a whole system approach to curriculum development can be taken that firstly, makes possible the creation of a framework for educators to articulate sustainable development as a meta-context of the curriculum, and secondly, encourages a whole system approach to considering sustainable development issues.

\section{SUSTAINABLE DEVELOPMENT AS A META-CONTEXT}

Engineering curriculum often addresses sustainable development as an 'aspect' of engineering rather than a central agenda, with ad hoc and highly variable references to topics ranging from pollution and resource consumption to safety, energy efficiency, recycling, fair trade, livelihood and public health. As long as that is the case, sustainable development will remain a consideration to be balanced by other aspects, like economic development and the financial wellbeing of the university, learning and teaching ambitions, or other agendas that flow through the higher education system. Unfortunately this kind of scenario is evident in numerous codes of ethics statements and graduate attribute expectations around the world [14].

In fact, while numerous discipline-based 'aspects' are covered by sustainable development, they are not often considered systemically nor understood for their nuances within each discipline. This is evidenced in research currently underway. For example, in Australia a project is currently underway, funded by the Federal Department of Resources, Energy and Tourism, to inquire into energy efficiency education and articulating meaningful graduate attributes and learning pathways for each of the major engineering disciplines. Engineers Australia is also seeking to encourage the embedding of sustainability within engineering curriculum. Alongside this endeavour, a systemic inquiry project is underway to define various disciplines, funded by the Australian Learning and Teaching Council, with one of the projects considering how twenty-first Century considerations are embedded within environmental engineering. 
Essentially such research points to a key problem, being that even in communities of practice related to sustainable development, the understanding of the term is often poor. The Brundtland definition of 'sustainable development' [6] is clear at the aggregate level of the whole planet Earth and global society. It remains challenging to distinguish what 'sustainable development' means within individual disciplines, or for various sub-topics, as there is no indisputable explanation/definition that prescribes how the global challenges should lead to individual action within those disciplines and sub-topics [16]. Further, a range of potential solutions have systemic implications that need to be considered across disciplines. For instance, should we increase bio-fuel production, or diminish it, to protect biodiversity? Should we recycle plastics, even if it creates safety risks and uses large amounts of energy? Ideally, engineering education should make students aware of these, and many other dilemmas associated with achieving sustainable engineering solutions. They should also be made aware that solutions are found through interactions with other disciplines and a range of stakeholders, through a whole of system approach.

The fact that a parameter (in this case sustainable development) is only meaningful at a specific level of aggregation is not new to engineers: For example, while in physics the concept of density is not applicable at sub-atomic level; still, characteristics of the atom are not irrelevant for density of a material. The same holds for sustainable development; while it may not be an appropriate 'category' to apply to a single technology, still, characteristics of the technology are relevant in considering whether sustainable development has been achieved. In saying this, if a whole of system approach to considering sustainability issues is not taken, then there may be a perception of conflicting needs to meet 'sustainable development'.

For example, considering the supply of power, certain aspects of delivering 'safe' power may not be the most energy efficient, however if we consider the notion of sustainable energy supply as a meta-context, it includes safety as a requirement. In another example, manufacturing low-embodied energy and low energy consuming white goods might require the use of almost depleted minerals. However, if we consider the notion of low carbon products, then the use of finite resources might be a requirement to achieve such a goal, with measures such as subsequent recovery at the end of the product life. Clearly, given the wide variety of contexts faced in any design scenario, engineering educators should not prescribe their students what to do when confronted with such dilemmas. Rather, there is a need for educators to develop students' capacity to deal with these situations in a whole system approach that is most likely to create consensus and among stakeholders and action towards improvement.

Given the emerging opportunity for systematic curriculum renewal, and given the need to clearly articulate sustainable development for all types of engineering, there are a number of emergent findings that span individual subjects through to accreditation considerations:

Engineering practice has as a core driver, 'doing things efficiently'. However, the question of 'how do we know what should be done?' should be a meta-context for the curriculum, to avoid the potential for 'doing the wrong things efficiently'. This includes for example addressing ethical considerations and dealing with community needs as central features of the engineering curriculum $[17,18]$.

- At the level of engineering courses/ subjects, statements about learning outcomes (which are intended to promote education for sustainable development) will also need to be specific to the actual knowledge or skill being developed, in the over-arching context of a whole system approach. These would be more effective 
than broad-brush and ad hoc statements that are not conducive to learning or assessment.

- At the level of engineering programs, generic statements may be counter-productive to curriculum renewal for sustainable development. Hence, statements about engineering graduate attributes will need to be more specific than simply stating competencies in 'sustainable development', and must articulate how a whole of system approach to engineering will be developed.

- At the level of directing capacity building (through engineering professional bodies and accreditation agencies), expectations about program and graduate competency requirements will need to be explicitly stated for whole of system considerations, during curriculum renewal towards education for sustainable development.

\section{CONCLUSIONS}

This paper has highlighted the phenomenon of how different articulations of the term 'sustainable development' can create dilemmas, particularly in the absence of a meta-context or whole of system approach. There is clearly a need for systemic appreciation of the term by engineering educators. Indeed, only by understanding the role of various articulations of sustainable development, could one proceed in actually making sustainable development the organizing theme of sustainable engineering curricula. With this context of systemic appreciation in mind, sustainability issues can then be addressed as a meta-context, avoiding the creation of dilemmas at the level of sub-discipline or design component. In conclusion, it is an urgent matter that engineers need to be skilled in whole of system processes that strategically consider sustainability issues, so that future solutions do not create future problems. This will involve action at multiple levels, from the individual subject and program through to professional discipline leadership in defining graduate attribute expectations and accreditation implications.

\section{REFERENCES}

1. Mulder, K., Sustainable Development for Engineers, a handbook and resource guide, Sheffield: Greenleaf, 2006

2. Sterling, S., Higher education, sustainability, and the role of systemic learning. In: Corcoran, P.B. \& Wals, A.E.J (Eds.) (2004). Higher Education and the Challenge of Sustainability: Problematic, Promise, and Practice. Dordrecht: Kluwer Academic Press, 2005

3. Jones, P., Selby, D. \& Sterling, S., Sustainability Education: Perspectives and Practice Across Higher Education, London Renouf: Publishing, 2010

4. Von Weizsäcker, E., Hargroves, K., Smith, M., Desha, C. \& Stasinopoulos, P., Factor 5: Transforming the Global Economy through $80 \%$ Increase in Resource Productivity, London: Earthscan, 2009

5. Smith, M., Hargroves, K. \& Desha, C., Cents and Sustainability - Securing Our Common Future by Decoupling Economic Growth from Environmental Pressures, The Natural Edge Project, London: Earthscan, 2010

6. Desha, C. \& Hargroves, K., Informing engineering education for sustainable development using a deliberative dynamic model for curriculum renewal, Proceedings of the Research in Engineering Education Symposium 2011, Madrid, 2011 
7. World Commission on Environment and Development (1987). Our Common Future, Oxford: Oxford University Press.

8. Stern, N., The Stern Review: The Economics of Climate Change, Cambridge: Cambridge University Press, 2006

9. Brown, L. (2007). Plan B 3.0: Mobilising to Save Civilisation, New York: W.W. Norton \& Company, www.earth-policy.org/Books/PB3/Contents.htm, [Accessed: 12-May-2011]

10. Desha, C., Hargroves, K. \& Smith, M., Addressing the time lag dilemma in curriculum renewal towards engineering education for sustainable development, International Journal of Sustainability in Higher Education, 10(2), pp 184-199, 2009 http://dx.doi.org/10.1108/14676370910949356

11. Desha, C. \& Hargroves, K. (2009). Surveying the State of Higher Education in Energy Efficiency, in Australian Engineering Curriculum, International Journal of Cleaner Production, 18(2010), pp 652-658, http://dx.doi.org/10.1016/j.jclepro.2009.07.004

12. Association for the Advancement of Sustainability in Higher Education (2010). Sustainability Curriculum in Higher Education: A Call to Action, Denver, Colorado.

13. Corcoran, P. \& Wals, A., Higher Education and the Challenge of Sustainability Problematics, Promise, and Practice, Boston: Kluwer Academic Publishers, 2008

14. Wals, A. (2008) (Ed.). From cosmetic reform to meaningful integration: implementing education for sustainable development in higher education institutes the state of affairs in six European countries, Amsterdam: DHO

15. Byrne, E., Desha, C., Fitzpatrick, J. \& Hargroves, K. Engineering Education for Sustainable Development: A Review of International Progress, in Proceedings of the 3rd International Symposium for Engineering Education, University College Cork, Ireland, 2010

16. Mulder, K.F., Ferrer-Balas, D., van Lente, H. 2011 (forthcoming). What is Sustainable Technology?, Sheffield: Greenleaf

17. Mulder, K., Engineering education in sustainable development: sustainability as a tool to open up the windows of engineering institutions. Business Strategy and the Environment, 13, pp 275-285, 2004, http://dx.doi.org/10.1002/bse.407

18. Lucena, J., Schneider, J. \& Leydens, J.A., Engineering and Sustainable Community Development. Ed. C. Baillie. San Rafael, CA: Morgan \& Claypool, 2010 